\title{
Inmunoestimulantes en teleosteos: Probióticos, $\beta$-glucanos y LPS
}

\section{Immunostimulants in teleost fish: probiotics, $\beta$-glucans and lipopolysaccharides}

\author{
Imunoestimulantes em teleósteos: Probióticos, \\ Beta-glucanas e LPS
}

\author{
Mónica A. Vásquez - Piñeros ${ }^{1 *}$, lang S. Rondón - Barragan ${ }^{2}$, Pedro R. Eslava- Mocha ${ }^{3}$ \\ 1* Bióloga Marina, MSc, ${ }^{2}$ MVZ,MSc, Grupo de Investigación en Inmunología y Fisiopatología Animal, \\ Universidad del Tolima, ${ }^{3} \mathrm{MV}, \mathrm{MSc}$. \\ * Grupo de Investigación en Sanidad de Organismos Acuáticos, Universidad de los Llanos. \\ Email: mandreavasquez@gmail.com
}

Recibido: septiembre 16 de $2011 \quad$ Aceptado: marzo 05 de 2012

\begin{abstract}
Resumen
Los inmunoestimulantes son principalmente, elementos estructurales de microorganismos, que basan su principio en la estimulación del sistema inmune innato, mostrando mejoramiento del estado sanitario de los animales e incremento de la resistencia frente a patógenos. Dentro de los inmunoestimulantes más utilizados en peces se encuentran los $\beta$-glucanos, los lipopolisacáridos y se incluyen las bacterias benéficas, denominadas probióticos. Los estudios realizados en peces se han enfocado en evaluaciones in vitro e in vivo de las respuestas celulares y humorales, la modulación de la transcripción génica y los efectos de resistencia frente a patógenos de interés; mostrando de manera general efectos positivos sobre el estado inmunológico de los peces y resistencia a enfermedades. La revisión propuesta intenta indagar sobre mecanismos de acción de algunos inmunoestimulantes de mayor uso, conceptualizar su uso en acuicultura y discutir acerca de trabajos recientes sobre el tema, lo cual servirá de base en el planteamiento de investigaciones pertinentes y factibles para abordar algunas problemáticas en el área sanitaria piscícola.
\end{abstract}

Palabras clave: acuicultura, enfermedad, peces, sanidad, sistema inmune.

\begin{abstract}
Immunostimulants mainly consist of microorganisms' structural elements whose principle is based on stimulating the innate immune system, leading to an improvement in animals' sanitary state and increased resistance to pathogens. $\beta$-glucans and lipopolysaccharides are some of the most used immunostimulants in the fish industry, including beneficial bacteria called probiotics. Studies on fish have been focused on the in vitro and in vivo evaluation of cellular and humoral responses, modulating gene transcription and the effects of resistance regarding pathogens of interest, usually having positive effects on the fishes' immunological state and resistance to disease. The proposed review was aimed at investigating the mechanisms of action of some of the most used immunostimulants, conceptualising their use in aquiculture and discussing recent work on the topic thereby forming the basis for proposing pertinent, feasible investigations for tackling some problems in the fish-farming health/sanitation area.
\end{abstract}


Key words: aquiculture, disease, fish, health/sanitation, immune system.

\begin{abstract}
Resumo
Os imunoestimulantes são principalmente elementos estruturais de microorganismos, que basam seu principio na estimulação do sistema imune inato, apresentando melhoramento do estado da saúde dos animais e maior resistência a patógenos. Entre os imunoestimulantes mais utilizados em peixes estão as -glucanas, os lipopolissacarídeos e incluso as bactérias benéficas, chamados probióticos. Estudos feitos em peixes têm-se centrado em avaliações in vitro e in vivo das respostas celulares e humorais, a modulação da transcrição de genes e os efeitos da resistência aos agentes patogênicos de interesse, em geral, mostrando efeitos positivos sobre o estado imunitário dos peixes e a resistência a doenças. A revisão proposta tenta indagar sobre os mecanismos de ação de alguns imunoestimulantes de mais uso, sua utilização em aquicultura e discutir acerca de trabalhos recentes sobre o assunto, que servirá de base para a formulação de pesquisas relevantes e viáveis para resolver alguns problemas na área da saúde de peixes.
\end{abstract}

Palavras chave: aqüicultura, doença, peixe, saúde, sistema imunológico.

\section{Introducción}

Actualmente, la piscicultura ha tenido un amplio crecimiento, constituyendo uno de los pilares de la economía pecuaria (Kapetsky y Nath, 1997; FAO, 2009; SOFIA, 2009); por esta razón se han diseñado alianzas estratégicas y redes internacionales que fortalezcan este sector, que estimulen los sistemas de producción y reduzcan el impacto ambiental (SOFIA, 2009; FAO, 2010). No obstante, el incremento en la presión de estos sistemas productivos, con el fin de ser más competitivos frente a las exigencias de los mercados y la necesidad de elevar la eficiencia, favorece la aparición de enfermedades principalmente en sistemas intensivos, por lo que se opta por la terapéutica antibiótica como respuesta inmediata, convirtiéndose de uso común en el sector. Se ha demostrado que el uso indiscriminado de antibióticos ha conllevado a la generación de bacterias resistentes, eliminación de bacterias benéficas que limita su competencia con microorganismos patógenos, compromete la respuesta inmune en niveles terapéuticos (Lunden y Bylund, 2002; Serezlí et al., 2005) y posee efectos deletéreos sobre el medio ambiente. Por tal razón, emerge la demanda de productos orgánicos, productos verdes, y en general productos ambientalmente amigables y favorables para la salud humana, que requieren de herramientas alternativas que no solo mitiguen la morbi-mortalidad, sino que mejoren la sostenibilidad y la calidad de los productos de los sistemas acuícolas. Aunque algunas sustancias como los inmunoestimulantes y los probióticos responden a esta necesidad, se requieren estudios rigurosos en diferentes especies de consumo que validen la efectividad del uso de estos productos de manera cotidiana, para el mejoramiento de la salud y sobrevivencia de los peces, y por ende la disminución del uso de antibióticos y antimicrobianos.

\section{Inmunoestimulantes}

\section{Definición y usos}

Los inmunoestimulantes se han definido como sustancias que potencian el sistema inmunitario $y$ aumentan la resistencia frente a las enfermedades infecciosas (Rodríguez et al., 2003). Raa (2000), los enmarca como compuestos químicos, los cuales existen como elementos estructurales principalmente de las bacterias, hongos miceliales y levaduras, que activan los leucocitos y por tanto confieren al animal mayor resistencia a las enfermedades causadas por virus, bacterias, hongos y parásitos. Por otro lado, Sahoo (2007), los definió como compuestos químicos, (sintéticos o naturales), que actúan sobre los mecanismos de respuesta inmune del hospedero para el control de patógenos.

A finales de la década de los ochenta comenzaron a emplearse inmunoestimulantes y probióticos en acuicultura, principalmente para aumentar la duración de la actividad de la respuesta inmunitaria inespecífica, que se caracteriza por tener un modo de acción generalizado (no actúan contra un microorganismo específico), por lo que tienen un uso profiláctico general (Rodríguez et al., 2003).

Dentro de los inmunoestimulantes se pueden encontrar: a) elementos estructurales de las bacterias (Lipopolisacáridos LPS, lipopéptidos, glicoproteínas capsulares y muramilpéptidos); b) productos de $\beta-1,3 / 1,6$ glucanos, provenientes de bacterias, hongos miceliales y levaduras; c) carbohidratos con estructuras complejas (glucanos) de varias fuentes biológicas incluyendo algas; péptidos presentes en extractos de ciertos animales o hechos por hidrólisis enzimática de proteínas de peces; nucleótidos y pro- 
ductos sintéticos; d) también se encuentran algunos alimentos poseedores de un efecto beneficioso sobre la salud (también conocidos como nutracéuticos) (Raa, 2000), vitaminas (C, E, A, D), carotenos, minerales (zinc, cobre, manganeso, cobalto, yodo, flúor, entre otros), que actúan principalmente como inmunomoduladores (Rondón, 2004); e) probióticos, definidos como microorganismos vivos que confieren un efecto fisiológico benéfico sobre el hospedero (Fuller, 1989), estos incluyen bacterias del genero LactobaciIlus, Carnobacterium, Vibrio, Enterococcus, Bacillus, Leuconostoc, Lactacoccus, Pediococcus y ShewaneIla y levaduras como Saccharomyces cerevisiae entre otros (Verschuere, 2000).

Los primeros estudios sobre inmunomodulación de teleósteos se realizaron in vitro $y$, posteriormente, in vivo. In vivo estas sustancias pueden administrarse por inyección (técnica costosa que implica manipulación de los peces), o bien disueltas en el agua, es decir, mediante baño de los animales (que también implica manipulación y con ello, estrés). El modo más reciente de aplicación de inmunoestimulantes es a través de la dieta, lo que ofrece muchas ventajas ya que resulta menos costoso y no implica manipulación de ejemplares (Rodríguez et al., 2003).

En la actualidad, se estudia su uso combinado con vacunas y antibióticos, así como el efecto de mezclas de inmunoestimulantes, evaluados a través de diferentes mecanismos de defensa inespecíficos; sin embargo, muchas veces los resultados son difíciles de evaluar y no ha sido fácil identificar un biomarcador efectivo para la resistencia a enfermedades en peces. Aoshima et al. (2005) (citado por Rodríguez et al., 2003), plantearon que un incremento en las respuestas de defensa no específicas in vitro no siempre reflejan el incremento de resistencia a la enfermedad, por tanto, las respuestas integradas adecuadas de varios mecanismos deben ser probadas con un desafío artificial estandarizado con un agente infeccioso. Así, la mayoría de reportes han descrito la resistencia a infecciones bacterianas principalmente en los desafíos de enfermedad (Nakagawa, 2007).

Dentro de los inmunoestimulantes más comúnmente utilizados en peces, se encuentran los $\beta$-glucanos (principalmente extraídos de la levadura Saccharomyces cerevisiae), los probióticos, especialmente el grupo de bacterias acido lácticas y lipopolisacáridos.

\section{Reconocimiento de los inmunoestimulantes}

Los inmunoestimulantes se caracterizan por tener repeticiones de ciertas moléculas (tales como gluco- sa, ribosa, ácidos grasos, ciertas lipoproteínas, entre otras) que son estructuras abundantes y conservadas en comunidades microbianas de procariotas (Dalmo y Bøgwald, 2008), y están ausentes o difieren en estructura de las células eucariotas, tales estructuras son denominadas: Patrones Moleculares Asociados a Microorganismos (MAMPs) y en el caso de los microorganismos que inducen enfermedad son denominados Patrones Moleculares Asociados a Patógenos (PAMPs) (estructuras encontradas también en microorganismos potencialmente patógenos) (Patiño, 2009).

Los PAMPs son capaces de unirse a receptores de células centinelas, como macrófagos, células dendríticas, células mast (para el caso de mamíferos) o granulares eosinofílicas para el caso de los peces. La unión de los PAMPs a los receptores, activa vías de señalización intracelular y causa que las células centinelas secreten moléculas que disparan la respuesta inmune (Tizard, 2009).

\section{$\beta$-glucanos}

\section{Estructura de $\beta$-glucanos}

El nombre de los $\beta$-glucanos proviene del prefijo Gluc, que significa poliglucosa y an, que es sufijo para (homopolisacáridos), $\beta$ (1,3)-D glucanos, es el termino más común para los homopolisacáridos que tienen uniones $\beta(1,3)$-D en el esqueleto, y también pueden poseer uniones $\beta$-D glucosídicas en posición 6 (Dalmo y Bøgwald, 2008) (Figura 1).

En la naturaleza, los $\beta$-glucanos se encuentran en plantas, algas, bacterias, hongos y levaduras (Selvaraj et al., 2005a). Los $\beta$-glucanos de las levaduras son carbohidratos que consisten en glucosa y manosa como principales constituyentes de la membrana celular (Dalmo y Bøgwald, 2008; Mantovani et al., 2008).

\section{Reconocimiento de $\beta$-glucanos}

Se ha hipotetizado que la colaboración de diferentes familias de receptores, así como las opsoninas no clásicas y las cascadas de proteínas como el complemento, son importantes mecanismos para mejorar la afinidad la adhesión a los $\beta$-glucanos. (Dalmo y Bøgwald, 2008). Dentro de los receptores más importantes de este compuesto se encuentran los receptores scavengers, que son receptores no opsónicos de baja afinidad, que pueden unirse a varias sustancias polianiónicas, como los $\beta$-glucanos sulfatados, sin embargo estos receptores no se relacionan con la unión e internalización de este compuesto. Se he reportado 


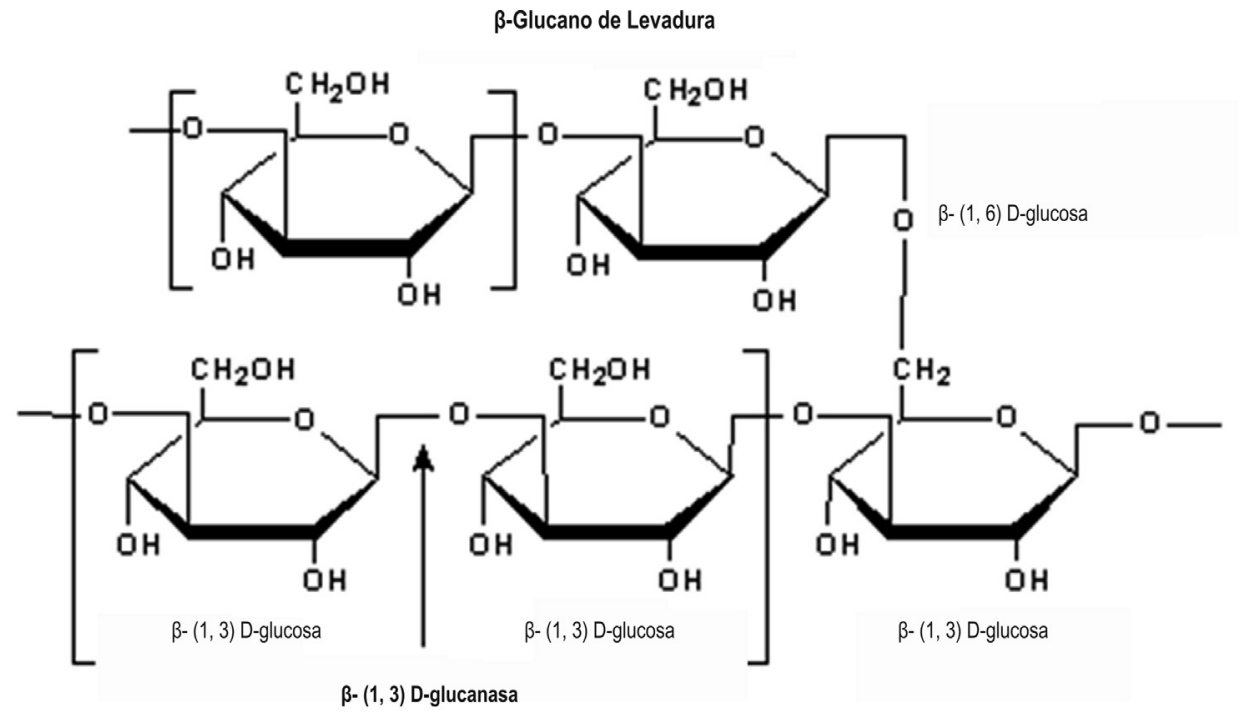

Polímero de $\beta$ - (1, 3) D con ramificaciones en unidades $\beta$ - $(1,6)$

Figura 1. Estructura de $\beta$-glucanos de la pared celular de una levadura (Tomado de Volman et al., 2008).

que el principal receptor de $\beta$-glucanos, es la Dectina-1, este receptor pertenece a los receptores similares a la lectina tipo $C$, que se une principalmente a ligados proteicos (Dennhy et al., 2007), media la señalización que induce la producción de IL-10 y la explosión respiratoria en neutrófilos. La cooperación de la Dectina 1 y el TRL2, también inducen la producción de IFN- $\gamma$, IL-2 y IL-12p40 (Tada et al., 2009; Rothfuchs et al., 2007), y la diferenciación de células Th1. Estudios recientes sugieren que la Dectina- 1 induce IL-17 para la producción de células Th17, tanto en humanos como en ratones (Palm y Medzhitov, 2007), en peces algunos de los genes inductores de IL-17, han sido clonados en zebrafish, trucha arco iris, y la lamprea (Gunimaladevi et al., 2006), y algunos están siendo clonados y caracterizados, como en Salmón de Atlántico (Dalmo y Bøgwald, 2008); en peces, la respuesta de estos genes es importante en la activación de células epiteliales, reclutamiento de neutrófilos, y para la migración de leucocitos hacia la mucosa por modulación de la expresión de receptores de quimioquinas. Otros receptores que pueden estar involucrados en la respuesta inducida por $\beta$-glucanos en peces puede ser la lactosilceramida, encontrado en leucocitos y células endoteliales, que induce la producción de especies reactivas de oxígeno (Chen, 2007), y los receptores de complemento tipo 3, de la familia de las $\beta 2$-integrinas, que controlan la síntesis de IL-2 en monocitos de humanos y afectan la inmunidad de células $\mathrm{T}$, aunque se ha revelado estudios de la formación del CR3 en carpas (Nakao et al., 2003), aun no se ha clonado los genes C3, en ningún pece hasta ahora (Dalmo y Bøgwald, 2008). Los receptores de $\beta$-glucanos se han encontrado en macrófagos de salmón del atlántico (Engstad et al., 1994) y neutrófilos del catfish (Ainsworth, 1994)

\section{Efecto de $\beta$-glucanos en peces}

Se ha demostrado que el reconocimiento de $\beta$-glucanos activa directamente los leucocitos, estimula la fagocitosis, la actividad citotóxica y antimicrobiana, incluyendo la producción de especies reactivas intermediarias de nitrógeno y oxígeno; adicionalmente, estos carbohidratos modulan la producción de mediadores proinflamatorios, citoquinas y quimioquinas, como IL-8 (Interleuquina-8), IL-1 $\beta$, IL-6 y TNF (Factor de necrosis tumoral alfa), otorgando una mejor y más rápida capacidad de respuesta, que repercute en una mayor resistencia a patógenos (Falco et al 2012; Carpang et al 2012; Refstie et al., 2012; Zhang et al., 2009; Kim y Zhang, 2009; Misra et al., 2006; Selvaraj et al., 2006).

En peces, se ha demostrado que el efecto de los $\beta$-glucanos varía con la especie de estudio, y depende de la cantidad incorporada en la dieta, la duración en la alimentación y temperatura ambiental. Los $\beta$-glucanos solubles pueden ser absorbidos por el intestino y por tanto ser nutritivos. Se ha demostrado su efecto en: inmunoestimulación de peces sanos, inmunoestimulación en peces inmunocomprometidos, inmunoestimulación por inyección (así como su efecto adyuvante), estimulación de la inmunidad adaptativa 
y su efecto junto a vacunas (Lin et al., 2011; El-Boshy et al., 2010; Kuntuu et al, 2009; Dalmo y Bøgwald, 2008; Selvaraj et al., 2006; Palic et al., 2006). Algunos de los estudios de inmunoestimulación por $\beta$-glucanos en peces, se resumen en la tabla 1.

Los $\beta$-glucanos, tienen el potencial de incrementar las tasas de supervivencia de peces, al menos al ser usado como medida profiláctica. Dietas con suplementos de $\beta$-glucanos son una opción interesante para mejorar la actividad defensiva y por tanto la resistencia a enfermedades, y su uso como adyuvante. Uno de los aspectos prometedores es su potencial para activar las células Th17 de los peces, que ofrece un incremento en la resistencia a enfermedades de la mucosa (Dalmo y Bøgwald, 2008).

\section{Estructura de los LPS}

Los lipopolisacáridos son componentes complejos de la membrana externa celular de bacterias Gram negativas, conocidos como endotoxinas. Generalmente son sustancias de gran peso molecular con una única estructura química, que consta de tres regiones: una región externa (conocida como antígeno $\mathrm{O}$, componente lineal o ramificado de residuos de oligosacáridos), una región de polisacáridos del núcleo (que consiste en cadenas cortas de azúcares), y una región interna rica en ácidos (i.e. lípido A con unidades de diglucosamina con ácidos grasos de cadena larga) (Swain et al., 2008; Madigan et al., 2009) (Figura 2).

Los animales superiores son extremadamente sensibles a la endotoxina, incluso a dosis bajas, pero vertebrados inferiores como las ranas y los peces son resistentes al choque endotóxico (Berczi et al., 1966 citado por Swain et al., 2008).

\section{Reconocimiento de LPS}

En mamíferos, el TLR4 es el principal componente del complejo receptor (CD14/TLR4/MD2) (receptores CD14 y TLR4 asociados a proteína MD-2) que está relacionado con la activación del sistema inmune por LPS.

EI LPS es capaz de unirse a la proteína de unión LBP (por sus siglas en inglés lipopolysaccharide binding protein), la unión se hace específicamente a través de la estructura endotóxica del LPS denominada lípido A; esta unión a su vez acelera la unión de la endotoxina al receptor CD14 que actúa junto con el complejo TLR4/MD2, resultando en la homodimerización y activación del TLR4 seguido del reclutamiento de las moléculas adaptadoras intracelulares (dentro de las cuáles participan la MyD88, TIRAP, TICAM 1 y TICAM 2 ), a través de sus dominios TIR, que por último permite la expresión de genes proinflamatorios (Fitzgerald et al., 2004).

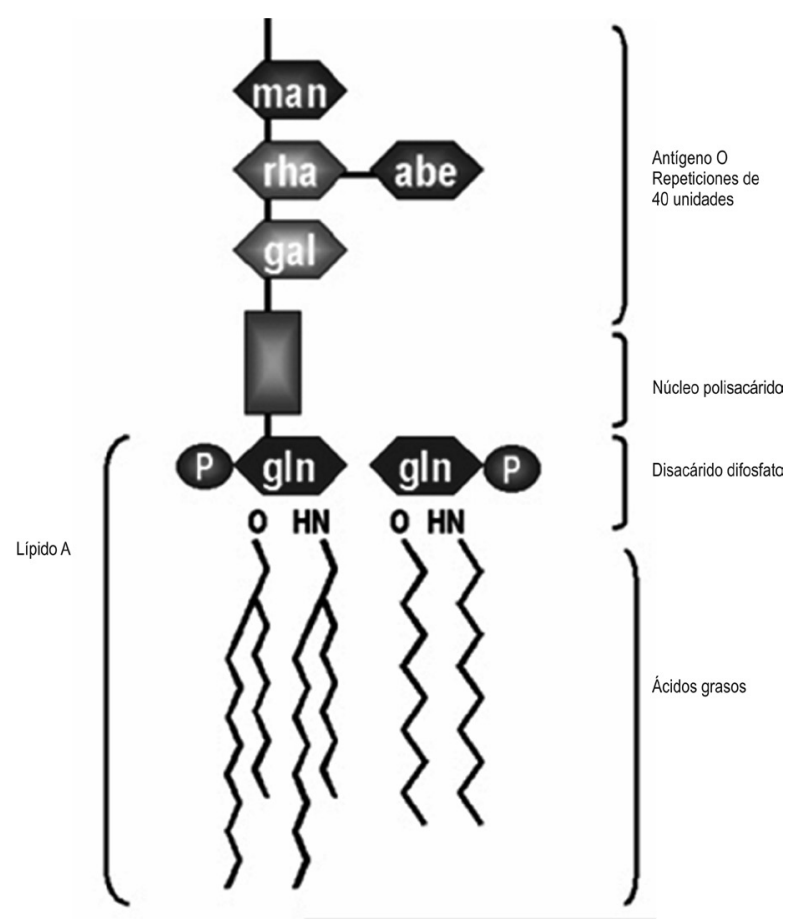

Figura 2. Unidad típica de polisacárido mostrando las diferentes regiones. (Modificado de Swain et al., 2008). 
Tabla 1. Estudios de $\beta$-glucanos como inmunoestimulantes en peces

\begin{tabular}{|c|c|c|c|c|c|}
\hline Especie & $\begin{array}{l}\text { Inmuno- } \\
\text { estimulante }\end{array}$ & Fuente & $\begin{array}{l}\text { Adminis- } \\
\text { tración }\end{array}$ & Efecto & Autor \\
\hline Gadus morhua & $\beta$-glucanos & $\begin{array}{l}\text { Saccharomyces } \\
\text { cerevisiaae }\end{array}$ & $\begin{array}{l}\text { Incubación } \\
\text { células } \\
\text { bazo }\end{array}$ & $\begin{array}{l}\text { Incrementa niveles de expresión de } \\
\text { genes, luego de } 3 \mathrm{~h} \text {, incrementa lisozima } \\
\text { tipo G, IL-8, GLUT } 1 \text { y } 4 \text {, luego de } 24 \\
\text { horas incrementa genes antibacteriales } \\
\text { BPL/LBP, GLUT } 2,3 \text { y } 4 \text {. }\end{array}$ & $\begin{array}{l}\text { Caipang } \\
\text { et al., } 2012\end{array}$ \\
\hline Cyprinus carpio & $\beta$-glucanos & MacroGard $®$ & Dieta & $\begin{array}{l}\text { Reduce niveles de expresión génica } \\
\text { de citoquinas inflamatorias (TNF } 1 \text { y } \\
2 \text {, IL-1 } \beta \text {, IL-6, IL-10), mejora respuesta } \\
\text { inflamatoria en riñón craneal posterior a } \\
\text { la exposición a A salmonicida. }\end{array}$ & $\begin{array}{l}\text { Falco et al., } \\
2012\end{array}$ \\
\hline Cyprinus carpio & $\beta$-glucanos & $\begin{array}{l}\text { Saccharomyces } \\
\text { cerevisiaae }\end{array}$ & Dieta & $\begin{array}{l}\text { Incrementa resistencia a A. veronii. } \\
\text { Mejora crecimiento, al día } 21 \\
\text { incrementa fagocitosis y actividad de } \\
\text { lisozima, fagocitosis, incremento de } \\
\text { leucocitos y explosión respiratoria, } \\
\text { los parámetros disminuyen al día } 51 \\
\text { de administración. Mejor efecto que } \\
\text { quitosan y rafinosa. }\end{array}$ & $\begin{array}{l}\text { Lin et al., } \\
2011\end{array}$ \\
\hline $\begin{array}{l}\text { Oreochromis } \\
\text { niloticus }\end{array}$ & $\beta$-glucanos & $\begin{array}{l}\text { Saccharomyces } \\
\text { cerevisiaae }\end{array}$ & Dieta & $\begin{array}{l}\text { Aumenta resistencia a Aeromonas } \\
\text { hydrophyla incremento actividad } \\
\text { fagocítica, actividad bactericida } \\
\text { del suero, niveles de óxido nítrico, } \\
\text { linfocitos. En animales expuestos } \\
\text { a cloruro de mercurio, incrementa } \\
\text { adhesión neutrófilos, sobrevivencia y } \\
\text { niveles de oxido nítrico. }\end{array}$ & $\begin{array}{l}\text { El-Boshy } \\
\text { et al., } 2010\end{array}$ \\
\hline Salmo salar & $\begin{array}{l}\beta-1,3 / 1,6 \\
\text { glucanos }\end{array}$ & $\begin{array}{l}\text { Saccharomyces } \\
\text { cerevisiaae }\end{array}$ & Dieta & $\begin{array}{l}\text { Redujo infestación pulga marina Caligus } \\
\text { elongatus, en peces alimentados con } \\
\text { harina de soya. No mejoro la enteritis } \\
\text { diarreica inducida por dietas con altos } \\
\text { contenido de harina de soya }\end{array}$ & $\begin{array}{l}\text { Refstie, } \\
\text { et al., } 2010\end{array}$ \\
\hline $\begin{array}{l}\text { Ctenopha- } \\
\text { ryngodon idella }\end{array}$ & $\beta$-glucanos & Poria cocos & Dieta & $\begin{array}{l}\text { Incremento actividad superoxido } \\
\text { dimutasa (SOD) y catalasa, expresiones } \\
\text { de genes } M x \text {, protección contra virus de } \\
\text { la carpa hervivora }\end{array}$ & $\begin{array}{l}\text { Kim y } \\
\text { Zhang, } \\
2009\end{array}$ \\
\hline Oncorhyncus mykiss & $\beta$-glucanos & $\begin{array}{l}\text { Laminaria } \\
\text { hyperborea }\end{array}$ & Baño & $\begin{array}{l}\text { Mayor expresión } 24 \text { horas post-baño } \\
\text { de genes proinflamatorios, IL-1 } \beta \text { TNF-, } \\
\text { IL-6 y aumenta interleuquinas anti- } \\
\text { inflamatorias IL-10, TGF- } \beta \text {. Luego del } \\
\text { cuarto baño no hubo diferencias. }\end{array}$ & $\begin{array}{l}\text { Zhang } \\
\text { et al., } 2009 .\end{array}$ \\
\hline Oncorhyncus mykiss & $\beta$-glucanos & $\begin{array}{l}\text { Saccharomyces } \\
\text { cerevisiaae }\end{array}$ & $\begin{array}{l}\text { Dieta } \\
\text { Intrape- } \\
\text { ritoneal }\end{array}$ & $\begin{array}{l}\text { Ambas vías de administración } \\
\text { incremento las especies reactivas de } \\
\text { oxígeno, actividad de la lisozima, } \\
\text { complemento, bacteriolítica. No } \\
\text { aumento la resistencia contra } \\
\text { Flavobacterium columnare }\end{array}$ & $\begin{array}{l}\text { Kuntuu } \\
\text { et al., } 2009\end{array}$ \\
\hline Sparus aurata & $\begin{array}{l}\text { S. cerevisiae } \\
\text { silvestre } y \\
\text { mutante }\end{array}$ & $\begin{array}{l}\text { Silvestre } \\
\text { (BMA64-1A); } \\
\text { Mutante con } \\
\text { inhibición de la } \\
\beta-1,3 \text { glucano } \\
\text { sintetasa }\end{array}$ & Dieta & $\begin{array}{l}\text { Cepa mutante: incremento lisozima, } \\
\text { fagocitosis, actividad citotóxica y } \\
\text { explosión respiratoria. Cepa silvestre: } \\
\text { aumento de actividad citotóxica y } \\
\text { explosión respiratoria ( } 4 \text { semana) }\end{array}$ & $\begin{array}{l}\text { Rodríguez } \\
\text { et al., } 2003\end{array}$ \\
\hline
\end{tabular}




\begin{tabular}{|c|c|c|c|c|c|}
\hline Especie & $\begin{array}{l}\text { Inmuno- } \\
\text { estimulante }\end{array}$ & Fuente & $\begin{array}{l}\text { Adminis- } \\
\text { tración }\end{array}$ & Efecto & Autor \\
\hline Pimephales promelas & $\beta$-glucano & $\begin{array}{l}\beta \text {-glucano } \\
\text { levadura } \\
\text { panadería }\end{array}$ & Dieta & $\begin{array}{l}\text { Incremento en degranulación de } \\
\text { neutrófilos en peces no estresados y } \\
\text { disminución en peces estresados }\end{array}$ & $\begin{array}{l}\text { Palic et al., } \\
2006\end{array}$ \\
\hline Cyprinus carpio & $\beta$-glucano & $\begin{array}{l}\text { Saccharomyces } \\
\text { cerevisiae }\end{array}$ & $\begin{array}{l}\text { Intrape- } \\
\text { ritoneal }\end{array}$ & $\begin{array}{l}\text { Incremento de leucocitos, actividad } \\
\text { bactericida y explosión respiratoria. } \\
\text { Mayor protección frente a A. hydrophila } \\
\text { con dosificación media. }\end{array}$ & $\begin{array}{l}\text { Selvaraj } \\
\text { et al.,2005a }\end{array}$ \\
\hline Labeo rohita & $\beta$-glucano & Comercial & Dieta & $\begin{array}{l}\text { Incremento de leucocitos, fagocitosis, } \\
\text { actividad lisozima, del complemento y } \\
\text { actividad bactericida luego de cuarenta } \\
\text { y dos días con } 250 \mathrm{mg} \beta \text { glucano } / \mathrm{kg}\end{array}$ & $\begin{array}{l}\text { Misra et al., } \\
2006\end{array}$ \\
\hline Danio rerio & $\beta$-glucano & $\begin{array}{l}\text { Saccharomyces } \\
\text { cerevisiae }\end{array}$ & Dieta & $\begin{array}{l}\text { Incremento en células monomielociticas } \\
\text { del riñón, mayor actividad bactericida } \\
\text { de células de riñón y modulación de la } \\
\text { expresión de IFN } \gamma \text { (interferón gama) y } \\
\text { quimioquinas. Mejora resistencia con } \\
\text { S. iniae }\end{array}$ & $\begin{array}{l}\text { Rodríguez } \\
\text { et al., } 2008\end{array}$ \\
\hline $\begin{array}{l}\text { Oreochromis } \\
\text { niloticus }\end{array}$ & $\beta$-glucano & Comercial & Dieta & $\begin{array}{l}\text { Los } \beta \text {-glucanos no tuvieron efecto } \\
\text { sobre la estimulación de la respuesta } \\
\text { de anticuerpos específicos a S. iniae } \\
\text { (en animales inmunizados), ni sobre la } \\
\text { resistencia a S. iniae }\end{array}$ & $\begin{array}{l}\text { Whittington } \\
\text { et al., } 2005\end{array}$ \\
\hline Cyprinus carpio & $\beta$-glucano & $\begin{array}{l}\text { Saccharomyces } \\
\text { cerevisiae }\end{array}$ & Dieta & $\begin{array}{l}\text { Intraperitoneal: Incremento } \\
\text { sobrevivencia a A. hydrophila, } \\
\text { leucocitos, producción de anión } \\
\text { superóxido, expresión de IL-1, efecto } \\
\text { adyuvante. }\end{array}$ & $\begin{array}{l}\text { Selvaraj } \\
\text { et al., 2005b }\end{array}$ \\
\hline
\end{tabular}

Sin embargo, según lliev et al. (2005), el complejo CD14/ TLR4/MD2 en peces está ausente, así como la LBP y la proteína adaptadora TICAM2, por lo que se explicaría la atenuada sensibilidad a los LPS en peces. Adicionalmente Novoa et al. (2009), reportó la tolerancia a LPS de larvas de zebrafish (entendiendo la tolerancia como una hiporespuesta a un segundo tratamiento de LPS luego de una primera exposición con dosis subletales de LPS), demostraron además que es este estado la producción de IL-1 disminuye, concordante con la respuesta de la inhibición de la expresión de TNF $\alpha$, IL-1 $\beta$, IL-6 y IL-12 en casos de tolerancia, adicionalmente reportaron que con larvas zebrafish Odysseus, mutantes del gen CXCR4, un receptor de quimioquina, o larvas silvestres tratadas con un inhibidor farmacéutico específico de CXCR4 expuestas a LPS, se obtenía una respuesta inflamatoria aguda y una reversión de la tolerancia a LPS, por lo que infirieron que el receptor CXCR4, es parte funcional del complejo sensible a los LPS y pudiese tener un papel en la inhibición de la cascada de señalización iniciada por TLR4. Sin embargo Sullivan et al., (2009), reporta que la falta de respuesta al LPS de E. coli coli y Legionella pneumophilia por parte del zebrafish es por la inhabilidad de TL-
R4a y el TRL4b de reconocer la molécula, más que por cambios en la capacidad de traducir las señales a través del domino (TIR) del receptor Toll/IL-1 Adicionalmente, según Illiev et al. (2005) el reconocimiento de leucocitos a los LPS puede estar dado por otras proteínas de unión a membrana como la CD11/CD18, también conocidas como $\beta$-integrinas; las proteínas de choque térmico 70 (HSP70), HSP 90, receptores de quimioquina, receptor CXCR4 y el factor de diferenciación 5 (GDF5). Las $\beta$-integrinas reconocen la estructuras hidrofílicas expuestas al ambiente de los carbohidratos de los LPS, no la parte hidrofóbica endotóxica (como es el caso de la LBP). Olive et al. (2005), hipotetízan la posibilidad que diferentes receptores, incluyendo TLRs, estén relacionados en la activación de los fagocitos mononucleares de peces, a través de las interacciones colaterales con las $\beta$-integrinas y la subsecuente transmisión de señales de activación intracelular (Figura 3).

\section{Efecto de LPS en peces}

Los LPS pueden disparar varios componentes inmunes en peces, así como mejorar su sobrevivencia (Swain et al., 2008). Se ha reportado inducción leve 


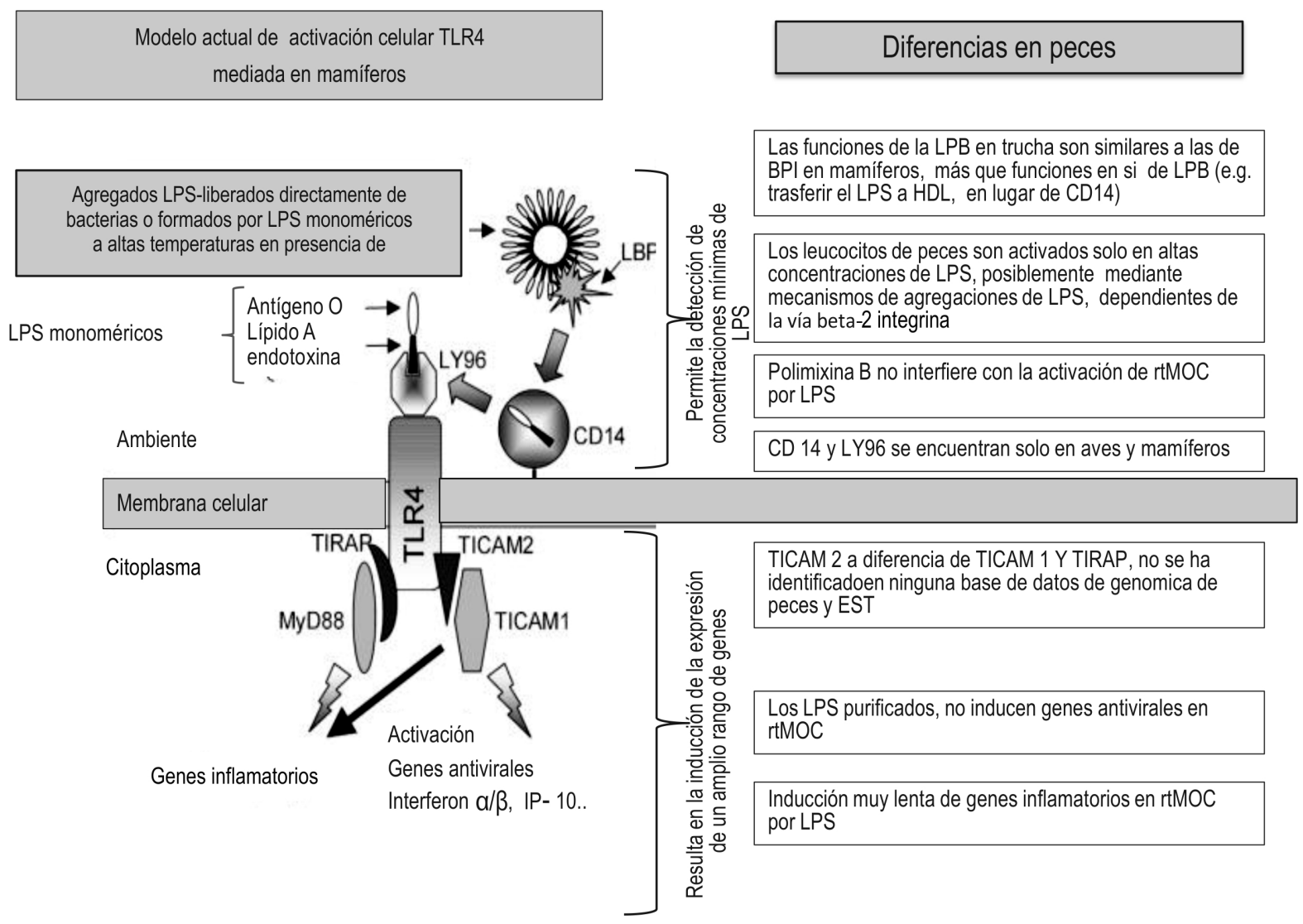

Figura 3. Esquema de las diferencias en entre peces y mamíferos a la respuesta por LPS (Modificado de Iliev et al., 2005).

de TNF-2 (factor de necrosis tumoral 2) en monocitos de Oncorhynchus mykiss (Iliev et al., 2005) con LPS de Escherichia coli, mejoramiento de la inmunidad y mejoramiento de la sobrevivencia inmunizando carpas comunes con LPS de A. hydrophila (Selvaraj et al., 2006). En la tabla 2, se resumen algunos de los trabajos en peces y su efecto sobre componentes inmunes, la tabla 3 presenta trabajos del uso combinado de LPS y $\beta$-glucanos.

\section{Bacterias probióticas}

La FAO/WHO (2001), define los probióticos como: microorganismos vivos que confieren un efecto fisiológico benéfico sobre el hospedero cuando se administran en cantidades adecuadas. Estos microorganismos son capaces de modular muchos aspectos principalmente los asociados al sistema inmune innato. La mayoría de las bacterias probióticas propuestas para el uso en acuicultura pertenecen a los géneros Lactobacillus, Lactococcus, Leuconostoc, Enterococcus, Carnobacterium, Shewanella, Bacillus, Aeromonas, Vibrio, Enterobacter, Pseudomonas, Clostridium, y Saccharomyces (Nayak, 2010).
El género Lactobacillus ha sido uno de los géneros más estudiados y más utilizados como probióticos, son generalmente reconocidas como seguros (GRAS por sus siglas en inglés Generally Recognized as Safe), pertenecen a la microbiota comensal gastrointestinal de humanos y animales, y se encuentra normalmente en alimentos fermentados junto con otras bacterias ácido lácticas (bacterias Gram positivas que producen ácido láctico como único (homofermentativas) o principal producto (heterofermentativas) de la fermentación de azucares (Kekkonen, 2008; Madigan, 2009). Por estas características la presente revisión se centra en el uso de Lactobacullis como probiótico en peces.

En Colombia, se han desarrollado pocos trabajos en el área. En 2004, se reportó por primera vez la utilización de microorganismos en la dieta de peces, en donde se evaluó el efecto de la inclusión de bacterias probióticas (Lactobacillus acidophillus y Bacillus subtilis) y prebióticos (pared de Saccharomyces cerevisiae) en la dieta para la alimentación de alevinos de cachama blanca (Piaractus brachypomus), como promotores del crecimiento (Pérez et al., 2004). Más 
Tabla 2. Estudios de efectos in vivo de LPS en peces (modificado de Swain et al., 2008)

\begin{tabular}{|c|c|c|c|c|}
\hline Especie & Fuente & Administración & Efecto & Autor \\
\hline Danio rerio & E. coli & Inmersión & $\begin{array}{l}\text { Mejora la actividad de citoquinas } \\
\text { proinflamatorias }\end{array}$ & Watze et al., 2007 \\
\hline Labeo rohita & E. coli & Intraperitoneal & $\begin{array}{l}\text { Incrementa niveles de lisozima, globulina } \\
\text { total, mieloperoxidasa y actividad de } \\
\text { explosión respiratoria }\end{array}$ & Nayak et al., 2008 \\
\hline Labeo rohita & E. coli & Intraperitoneal & $\begin{array}{l}\text { Disminuye niveles de lisozima, globulina } \\
\text { total, mieloperoxidasa y actividad de } \\
\text { explosión respiratoria }\end{array}$ & Nayak et al., 2009 \\
\hline G. morhua & A. salmonicida & Dieta y baño & $\begin{array}{l}\text { Incrementa la sobrevivencia ante desafío con } \\
\text { A. salmonicida. }\end{array}$ & Konzisca et al., 2004 \\
\hline Salmo salar & $\angle P S$ & Baño & $\begin{array}{l}\text { Incrementa actividad de lisozima en riñón } \\
\text { craneal, intestino de macrófagos y células } \\
\text { polimorfonucleares }\end{array}$ & Paulsen et al., 2003 \\
\hline Sparus aurata & E. coli & Baño & $\begin{array}{l}\text { Incrementa actividad antiproteasa. Mejora } \\
\text { protección contra Photobacterium damsela }\end{array}$ & Hanif et al., 2005 \\
\hline Salmo salar & $\begin{array}{l}\text { Aeromonas } \\
\text { salmonicida }\end{array}$ & Inmunización & Mejora el nivel de anticuerpos específicos & Albut et al., 1998 \\
\hline Salmo salar & $\angle P S$ & In vivo & $\begin{array}{l}\text { Mejora fagocitosis, actividad pinocitosis, } \\
\text { producción de anión superóxido intracelular }\end{array}$ & Baba et al., 1988 \\
\hline Oncorhynchus mykiss & $\begin{array}{l}\text { Aeromonas } \\
\text { salmonicida }\end{array}$ & Intraperitoneal & $\begin{array}{l}\text { Incrementa la titulación de anticuerpos que } \\
\text { persisten hasta por 2-4 semanas }\end{array}$ & Nakhla et al., 1997 \\
\hline
\end{tabular}

recientemente, se reportó un mejoramiento de la tasa de conversión alimenticia, tasa de crecimiento específico e incremento diario de peso en tilapias nilóticas alimentadas con Bacillus y Lactobacillus (Martínez et al., 2008a), adicionalmente los autores revelaron antagonismo in vitro de Lactobacillus casei y Lactobacillus acidophilus contra dos patógenos de peces Streptococcus agalactiae y Aeromonas hydrophila, paralelamente realizaron ensayos in vivo, donde se demostró mayor sobrevivencia de peces alimentados con Bacillus sp., y Lactobacillus casei y desafiados a estos patógenos (Martínez et al., 2008b). Sin embargo, a pesar de los resultados favorables, tanto en productividad como sobre el estado de salud de los peces, la investigación en esta área es aún muy incipiente en el país, limitando su uso y aplicación tecnológica que favorecería la productividad de los sistemas piscícolas en Colombia.

\section{Mecanismo de acción y efecto en peces}

Los probióticos ha mostrado modular la composición y el metabolismo de la microbiota comensal, la competencia con patógenos incluyendo la inhibición o bloqueo de su adhesión, e inducir la producción de mucina, adicionalmente es capaz de producir com- puestos antimicrobianos, como ácidos orgánicos, peróxido de hidrógeno, ácidos grasos de cadena corta y bacteriocinas que refuerzan la barrera intestinal, ayudan a la regeneración de células epiteliales y al reforzamiento de las uniones estrechas de los enterocitos e incrementan los niveles de linfocitos intraepiteliales y granulocitos acidófilos en la mucosa (Pirarat et al., 2011; Kekkonen, 2008; Vásquez et al., 2005). En el caso de los peces alimentados con Lactobacillus sp., se ha demostrado protección contra las enfermedades infecciosas de los peces, tales como las causadas por la enfermedad del virus linfocitico (LCDV), $S$. iniae, S. parauberis, A. hydrophila, A. salmonicida, Edwardsiella tarda y Vibrio anguillarum, (Harikrishnan et al., 2010a; Harikrishnan et al., 2010b; Aly et al., 2008; El-Boshy et al., 2010; Balcázar et al., 2006, Nopadon, et al., 2006; Taoka et al., 2006; Kim y Austin, 2006; Nopadon et al., 2006); colonización del intestino por periodos de tiempo en que se suministra el probiótico y después de hasta tres semanas y cuatro semanas (Son et al., 2009; Kim y Austin, 2006; Chang y Liu, 2002); mejoramiento de la respuesta inmune, incrementando la expresión de genes proinflamatorios y anti-inflamatorios (Falco et al., 2012; Carpang et al., 2012); la expresión de receptores en la mucosa que disparan la respuesta inmune innata (Maldonado et 
Tabla 3. Estudio in vivo del efecto de mezclas de componentes microbianos, administrados por diferentes vías

\begin{tabular}{c|c|c|c|c|c}
\hline Tabla & Inmunoestimulante & Fuente & Administración & Efecto & Autor \\
\hline $\begin{array}{c}\text { Cyprinus } \\
\text { carpio }\end{array}$ & $\beta$-glucano y LPS & $\begin{array}{c}\beta \text {-glucano de } \\
\text { Saccharomyces } \\
\text { cerevisiae y LPS } \\
\text { de Aeromonas } \\
\text { hydrophila }\end{array}$ & $\begin{array}{c}\text { Dieta } \\
\text { Baño } \\
\text { Intraperitoneal }\end{array}$ & $\begin{array}{c}\text { El suministro intraperitoneal (IP) y oral } \\
\text { mejoró la resistencia A. hydrophila, } \\
\text { Incremento de monocitos y neutrófilos, } \\
\text { anión superóxido y mejoró efecto } \\
\text { adyuvante (IP). La administración } \\
\text { en baño no mostró respuesta. }\end{array}$ & $\begin{array}{c}\text { Selvaj } \\
2006\end{array}$ \\
\hline
\end{tabular}

al., 2007), el incremento de la actividad fagocítica, actividad del complemento, explosión respiratoria, expresión de citoquinas, actividad de la lisozima, actividad citotóxica de leucocitos (Falco et al., 2012; Carpang et al., 2012; El-Boshy et al., 2010; Kuntuu et al., 2009; Son et al., 2009; Harikrishana et al., 2010 a y b; Harikrishana et al., 2011 a y b; Wang et al., 2008; Panigrahi et al., 2007; Balcázar et al., 2006), e interferencia del Quorum sensing de bacterias (Nguyen et al., 2008), que se refiere al mecanismo por el cual los miembros de una población bacteriana se comportan cooperativamente, como respuesta a la densidad de la población. Adicionalmente, algunos trabajos se han enfocado en el uso de probióticos para el mejoramiento de parámetros productivos como ganancia de peso, eficiencia de retención de proteína, entre otros, asociando estas propiedades a la actividad de enzimas de las bacterias, que mejoran la utilización de nutrientes en los peces (Saha et al., 2006; Haroun et al., 2006; Yanbo y Zirong, 2006; Wang et al., 2008).

La tabla 4 resume algunos de los trabajos recientes realizados probióticos y su efecto tanto in vitro como in vivo en peces de cultivo.

\section{Algunas hipótesis involucradas en los mecanismos de acción de los probióticos sobre el sistema inmune de peces}

Además de los mecanismos anteriormente descritos de protección al hospedero por acción de los probióticos, se hipotetiza que existen mecanismos alternativos que pueden estar influyendo la respuesta inmune del hospedero.

Células de Paneth/CGE. La respuesta inmune en el intestino depende en gran parte de la presencia de células (ej. células caliciformes, células Paneth) especializadas en la producción de moléculas con funciones inmunes (criptidinas o $\alpha / \beta$-defensinas) o implicadas en la renovación del epitelio intestinal o de la expresión de moléculas de superficie, incluyendo lectinas (Keshav, 2006); aunque no existen células Paneth descritas en peces, Sveinbjørnsson et al., (1996) des- cribieron las células granulares eosinofílicas/células mast (CGE/CM) como análogas a las células de Paneth de los mamíferos, dada su secreción de lisozima así como su localización asociada al tracto gastrointestinal (Fawcett, 1987) y la capacidad de regenerar sus gránulos (Sveinbjørnsson, 1996; Rumio et al., 2004). Así como las células Paneth en mamíferos, sus análogas, las CGE en peces han guiado a la hipótesis de que estas podrían reconocer las bacterias probióticas que ingresan a la cripta, a través del TLR9 localizado en los gránulos secretorios, permitiendo la liberación de sustancias antimicrobianas.

Adicionalmente, se ha demostrado que ciertas células epiteliales activan genes que codifican defensinas, (moléculas descritas en peces, específicamente defensinas $\beta$ ), (Zou et al., 2007 y Falco et al., 2008) o expresan matrilisina en respuesta al contacto con bacterias (Rumio et al., 2004; López-Boado et al., 2000), las defensinas pueden tener actividad antiviral, probablemente por inducción del interferón tipo I, y tener propiedades quimiotácticas para las células dendríticas (Keshav, 2006), de esta manera median respuestas inflamatorias y el reclutamiento celular en la mucosa, como lo observado en peces alimentados con cepas de Lactabacillus $s p$., en donde se incrementa la población de linfocitos intraepiteliales y granulocitos en la mucosa intestinal (Pirarat et al., 2011; Picchietti et al., 2009), de tal forma que, tanto la posible función de las CGE como la estimulación para la producción de $\beta$-defensinas, pueden estar involucrados dentro de los mecanismos de inmunomodulación por bacterias acido lácticas en peces.

Fucosilación. Por otra parte, se ha demostrado que los glicoconjugados juegan un papel clave en las interacciones célula blanco-patógeno por un lado y en la protección de las células epiteliales por otro a través de un glicocalix altamente glicosilado (Lelouard et al., 1999; Ma et al., 2006; Sharon, 2006). Umeaski y Ohara (1989) demostraron que la actividad de la glicolípido fucosil-transferasa fue inducida por la introducción de bacterias en el tracto intestinal de animales axénicos. 
Tabla 4. Estudios de Lactobacillus como probióticos en peces

\begin{tabular}{|c|c|c|c|c|c|}
\hline Especie & Сера & Fuente & Administración & Efecto & Autor \\
\hline $\begin{array}{l}\text { Paralichtys } \\
\text { olivaceus }\end{array}$ & $\begin{array}{l}\text { L. plantarum, } \\
\text { L. acidophillus } \\
\text { L. brevis, } \\
\text { Bacillus subtillis, } \\
\text { Saccharomyces } \\
\text { cerevisiae }\end{array}$ & Laboratorio & $\begin{array}{l}\text { Mezcladas en la } \\
\text { dieta }\end{array}$ & $\begin{array}{l}\text { En peces desafiado con S. parauberis la } \\
\text { mezcla incrementó la actividades enzimáticas } \\
\text { de la SGOT y la SGPT de la cuarta a la } \\
\text { semana } 12 \text {. Se incrementó también la } \\
\text { actividad de la lisozima, fagocítica y del } \\
\text { complemento. }\end{array}$ & $\begin{array}{l}\text { Harikrishnan } \\
\text { et al., 2011a }\end{array}$ \\
\hline $\begin{array}{l}\text { Paralichtys } \\
\text { olivaceus }\end{array}$ & $\begin{array}{l}\text { L. plantarum, } \\
\text { L. acidophillus } \\
\text { L. sakei, } \\
\text { Saccharomyces } \\
\text { cerevisiae }\end{array}$ & Laboratorio & $\begin{array}{l}\text { Dieta cepas } \\
\text { individuales }\end{array}$ & $\begin{array}{l}\text { L. plantarum otorgó mayor protección } \\
\text { contra Uronema marinum. L. plantarum, L. } \\
\text { acidophullis y S. cerevisiae, incrementaron } \\
\text { la actividad de GOT, GPT, la producción } \\
\text { de anión superóxido y la actividad de la } \\
\text { lisozima. }\end{array}$ & $\begin{array}{l}\text { Harikrishnan } \\
\text { et al., 2011b }\end{array}$ \\
\hline $\begin{array}{l}\text { Oreochromis } \\
\text { niloticus }\end{array}$ & $\begin{array}{l}\text { Lactobacillus } \\
\text { rhamnosus GG }\end{array}$ & Humanos & Dieta & $\begin{array}{l}\text { Incrementa la altura del vello especialmente } \\
\text { de la parte media y proximal del intestino. } \\
\text { Incrementó linfocitos intraepiteliales, } \\
\text { granulocitos acidofilicos, la actividad del } \\
\text { complemento, fagocitica y bactericida de } \\
\text { los leucocitos del riñon craneal. incrementa } \\
\text { TNF } \alpha, \text { IL-1. }\end{array}$ & $\begin{array}{l}\text { Pirarat et al., } \\
2011\end{array}$ \\
\hline $\begin{array}{l}\text { Paralichtys } \\
\text { olivaceus }\end{array}$ & Lactobacillus sp & No reporta & $\begin{array}{l}\text { Dieta solo o en } \\
\text { mezcla }\end{array}$ & $\begin{array}{l}\text { Administración solo o en mezcla (con } \\
\text { sporolac), aumenta la producción de anión } \\
\text { superóxido, actividad fagocítica, actividad } \\
\text { del complemento y lisozima del plasma. } \\
\text { Incrementa la resistencia enfermedad del virus } \\
\text { del linfocisitis (LCDV) }\end{array}$ & $\begin{array}{l}\text { Harikrishnan } \\
\text { et al., 2010 }\end{array}$ \\
\hline $\begin{array}{l}\text { Epinephelus } \\
\text { bruneus }\end{array}$ & $\begin{array}{l}\text { Lactobacillus } \\
\text { sakei BK } 19\end{array}$ & Lenguado & Dieta & $\begin{array}{l}\text { Incrementa protección contra S. iniae, S. } \\
\text { parauberis suministrando por dos semanas } \\
\text { luego del desafío, incrementó actividad de la } \\
\text { catalasa y fagocítica de macrófagos del riñón } \\
\text { craneal, y la actividad de la lisozima }\end{array}$ & $\begin{array}{l}\text { Harikrishnan } \\
\text { et al., 2010 }\end{array}$ \\
\hline $\begin{array}{l}\text { Epinephelus } \\
\text { coioides }\end{array}$ & $\begin{array}{l}\text { Lactobacillus } \\
\text { plantarum }\end{array}$ & $\begin{array}{l}\text { Epinephelus } \\
\text { coioides }\end{array}$ & Dieta & $\begin{array}{l}\text { Mayor resistencia a Streptococcus sp., y } \\
\text { iridovirus. Incrementó la actividad del } \\
\text { complemento, de la lisozima, la GPx, la } \\
\text { actividad fagocítica y explosión respiratorio } \\
\text { de leucocitos del riñón craneal. La población } \\
\text { probiótica se incremento después del } \\
\text { suministro pero disminuyó después de una } \\
\text { semana }\end{array}$ & $\begin{array}{l}\text { Son et al., } \\
2009\end{array}$ \\
\hline $\begin{array}{l}\text { Dicentrarchus } \\
\text { labrax }\end{array}$ & $\begin{array}{l}\text { Lactobacillus } \\
\text { delbrueckii } \\
\text { subsp } \\
\text { delbrueckii }\end{array}$ & $\begin{array}{l}\text { Dicentrarchus } \\
\text { labrax }\end{array}$ & Dieta con artemia & $\begin{array}{l}\text { En larvas, incrementó la densidad de células } \\
\text { T y granulocitos acidofilicos en la mucosa } \\
\text { intestinal, disminuyó transcripción de genes } \\
\text { proinflamatorios (Cox } 2, \text { TGF- } \beta \text {, IL-1 } \beta \text { y IL-10) }\end{array}$ & $\begin{array}{l}\text { Picchietti, } \\
\text { et al } 2009\end{array}$ \\
\hline Ninguna & $\begin{array}{l}\text { Lactobacillus } \\
\text { plantarum JK-8 } \\
\text { Lactobacillus } \\
\text { hilgardi JK-11 }\end{array}$ & $\begin{array}{l}\text { Aguas } \\
\text { residuales de } \\
\text { cultivo de } \\
\text { camarón }\end{array}$ & $\begin{array}{l}\text { Incubación con } \\
\text { patógenos y } \\
\text { concentraciones } \\
\text { de amonio, nitrito } \\
\text { y nitrato }\end{array}$ & $\begin{array}{l}\text { El sobrenadante de las cepas lácticas } \\
\text { removieron los patógenos Vibrio harvey, V. } \\
\text { parahemolyticus y Edwardsiella tarda. Las } \\
\text { cepas probióticas removieron } 400 \mu \mathrm{M} \mathrm{NH}_{4}+\text {, } \\
\mathrm{NO}_{2}, \mathrm{NO}_{3} \text {. }\end{array}$ & $\begin{array}{l}\text { Ma, et al., } \\
2009\end{array}$ \\
\hline $\begin{array}{l}\text { Oncorhynchus } \\
\text { mykiss }\end{array}$ & $\begin{array}{l}\text { Lactobacillus } \\
\text { rhamnosus }\end{array}$ & Laboratorio & Dieta & $\begin{array}{l}\text { Incremento de anión superóxido por } \\
\text { leucocitos del riñón cefálico y actividad } \\
\text { del complemento. Sobre-regulación genes } \\
\text { expresan IL } 1 \beta 1 \text {, TNF, y TGF en bazo y riñón } \\
\text { cefálico }\end{array}$ & $\begin{array}{l}\text { Panigrahi et } \\
\text { al., } 2007\end{array}$ \\
\hline
\end{tabular}




\begin{tabular}{|c|c|c|c|c|c|}
\hline Especie & Сера & Fuente & Fuente & Efecto & Autor \\
\hline Sparus aurata & L. delbrüeckii & Sparus aurata & Dieta & $\begin{array}{l}\text { Incremento en actividad citotóxica y el } \\
\text { mantenimiento de fagocitosis luego de tres } \\
\text { semanas de alimentación. }\end{array}$ & $\begin{array}{l}\text { Salinas } \\
\text { et al., } 2008\end{array}$ \\
\hline $\begin{array}{l}\text { Oncorhynchus } \\
\text { mykiss }\end{array}$ & $\begin{array}{l}\text { L. sakei } \\
\text { Lactocuccus } \\
\text { lactis }\end{array}$ & $\begin{array}{l}\text { Oncorhynchus } \\
\text { mykiss }\end{array}$ & Dieta & $\begin{array}{l}\text { Incremento de actividad fagocítica de } \\
\text { Aeromonas salmónida inactivada por } \\
\text { leucocitos del intestino de peces alimentados } \\
\text { con la cepas probióticas, hubo mayor } \\
\text { incremento con L. lactis. }\end{array}$ & $\begin{array}{l}\text { Balcázar, et } \\
\text { al., } 2006\end{array}$ \\
\hline Sparus aurata & $\begin{array}{l}\text { L. fructivorans } \\
\text { L. plantarum }\end{array}$ & Heces humanas & $\begin{array}{l}\text { Cepas mezcladas } \\
\text { con alimento vivo }\end{array}$ & $\begin{array}{l}\text { La mezcla incremento el número de células } \\
\text { Ig+ y granulocitos acidófilos al día } 99 \text { post- } \\
\text { eclosión de las larvas }\end{array}$ & $\begin{array}{l}\text { Picchietti et } \\
\text { al., } 2007\end{array}$ \\
\hline Sparus aurata & $\begin{array}{l}\text { L.delbrüeckii } \\
\text { subsp. Lactis }\end{array}$ & Laboratorio & In vitro & $\begin{array}{l}\text { Incremento in vitro de fagocitosis y explosión } \\
\text { respiratoria de leucocitos }\end{array}$ & $\begin{array}{l}\text { Salinas et } \\
\text { al., } 2006\end{array}$ \\
\hline $\begin{array}{l}\text { Scophthalmus } \\
\text { maximus }\end{array}$ & $\begin{array}{l}\text { L. Acidophilus } \\
\text { L. brevis } \\
\text { L. casei ssp. } \\
\text { casei } \\
\text { L. delbrüeckii } \\
\text { ssp lactis } \\
\text { L. helveticus } \\
\text { L. plantarum } \\
\text { L. lactis ssp. } \\
\text { Lactis }\end{array}$ & $\begin{array}{l}\text { Leche } \\
\text { Cerveza } \\
\text { Queso } \\
\text { Carne } \\
\text { fermentada } \\
\text { Queso gruyer } \\
\text { Ensilado de } \\
\text { pasto } \\
\text { Leche }\end{array}$ & In vitro & $\begin{array}{l}\text { Se observó antagonismo in vitro de todas las } \\
\text { cepas lácticas a Vibrio splendius, V. pelagius, } \\
\text { V. alginolyticus, Carnobacterium piscícola } \\
\text { por la producción de ácido acético y ácido } \\
\text { láctico más que por las bacteriocinas. }\end{array}$ & $\begin{array}{l}\text { Vásquez, et } \\
\text { al, } 2005\end{array}$ \\
\hline $\begin{array}{l}\text { Oncorhynchus } \\
\text { mykiss }\end{array}$ & L. rhamnosus & Humano & Dieta & $\begin{array}{l}\text { Incrementa resistencia a Aeromonas } \\
\text { salmónida }\end{array}$ & $\begin{array}{l}\text { Nikoske- } \\
\text { lainen et al., } \\
2003\end{array}$ \\
\hline $\begin{array}{l}\text { Oreochromis } \\
\text { niloticus }\end{array}$ & L. rhamnosus & LAB & Dieta & $\begin{array}{l}\text { Incrementa resistencia a E. tarda, actividad } \\
\text { fagocítica y actividad del complemento por } \\
\text { vía alterna y prevención de necrosis tímica. }\end{array}$ & $\begin{array}{l}\text { Nopadon et } \\
\text { al., } 2006\end{array}$ \\
\hline $\begin{array}{l}\text { Oncorhynchus } \\
\text { mykiss }\end{array}$ & L. rhamnosus & LAB & Dieta & $\begin{array}{l}\text { Incremento de actividad fagocítica y de } \\
\text { complemento con forma activa. Incremento } \\
\text { de inmunoglobulina solo durante } \\
\text { alimentación. }\end{array}$ & $\begin{array}{l}\text { Panigrahi et } \\
\text { al., } 2005\end{array}$ \\
\hline $\begin{array}{l}\text { Oreochromis } \\
\text { niloticus }\end{array}$ & $\begin{array}{l}\text { Lactobacillus } \\
\text { acidophillus }\end{array}$ & Comercial & Dieta & $\begin{array}{l}\text { Incrementa niveles de lisozima, migración de } \\
\text { neutrófilos y actividad bactericida del plasma. } \\
\text { Mejor resistencia a Edwardsiella tarda. }\end{array}$ & $\begin{array}{l}\text { Taoka, et al., } \\
2006\end{array}$ \\
\hline
\end{tabular}

Aparentemente, dos programas de diferenciación toman lugar durante la diferenciación en las criptas. Esto guía a la expresión de diferentes glicosil-transferasas 0 acetil transferasas las cuales participan en la síntesis de ambientes glicosídicos en el borde libre en cepillo de los enterocitos (Maury et al., 1995) y dicho proceso puede ser dependiente del contenido de fibra en la dieta (Tardy et al., 1995).

Trabajos de Matsumura et al. (1999) describen proteínas similares a lectinas en cepas probióticas, las cuales contribuyen a la adherencia a la mucosa del intestino del hospedero. Se sugiere que algunas de estas proteínas similares a lectina reconocen la estructura de carbohidratos interna más que la estructura de carbohidratos externa (L- Fucosa, N- acetil D- Galactosamina y acido $\mathrm{N}$-acetil murámico).

Freitas et al. (2003) han descrito que la modulación por parte de las bacterias de la fucosilación (incremento en la producción de L-fucosa) de la superficie de los enterocitos permite un control de otras poblaciones bacterianas. Además, se ha demostrado que el intercambio de señales cruzadas del epitelio y las bacterias permite la regulación en la secreción de matrilisina, una metaloproteasa relacionada con el control de las pro-defensinas. Se ha demostrado que algunas bacterias, como Bacterioides thetaiotaomicron, son capaces de incrementar específicamente la galactosilación de las células epiteliales, sin embar- 
go el patrón de expresión es especifico a la bacteria, siendo así que la exposición a Lactobacillus casei, incrementó la expresión de galactosa y ácido siálico y disminuyó la de la $\mathrm{N}$-acetil glucosamina (Freitas et al., 2003). Dicha glicosilación puede tener un papel importante en limitar la entrada de virus intestinales. Recientemente, Irie et al. (2004) demostraron que algunos glicoesfingolípidos como Galactosil- $\beta 1$ ceramida, son capaces de reconocer y unirse a bacterias como $V$. anguillarum, siendo reconocido como receptor para la adhesión de esta bacteria al intestino de la trucha arcoiris (Figura 4).

\section{Conclusiones y perspectivas}

El uso de inmunoestimulantes en piscicultura posee un gran potencial como herramienta preventiva y de manejo sanitario. Han despertado gran interés por tener un modo de acción generalizado, capaces de aumentar la respuesta inmunitaria específica, respondiendo ante varios microorganismos patógenos y pudiéndose utilizar de manera profiláctica. Sin embargo, actualmente, el sector productivo piscícola colombiano se encuentra ante una gran oferta de sustancias o productos para mejorar las condiciones sanitarias, esto sin respaldo técnico ni rigor científico.

Por esta razón, se hace necesaria la realización de trabajos de investigación tendientes a definir la respuesta que generan principalmente en el sistema inmune innato, para su uso profiláctico; estudios que se pueden extrapolar de estudios previos en especies similares adecuando metodologías para evaluación en condiciones locales, que puedan responder, por

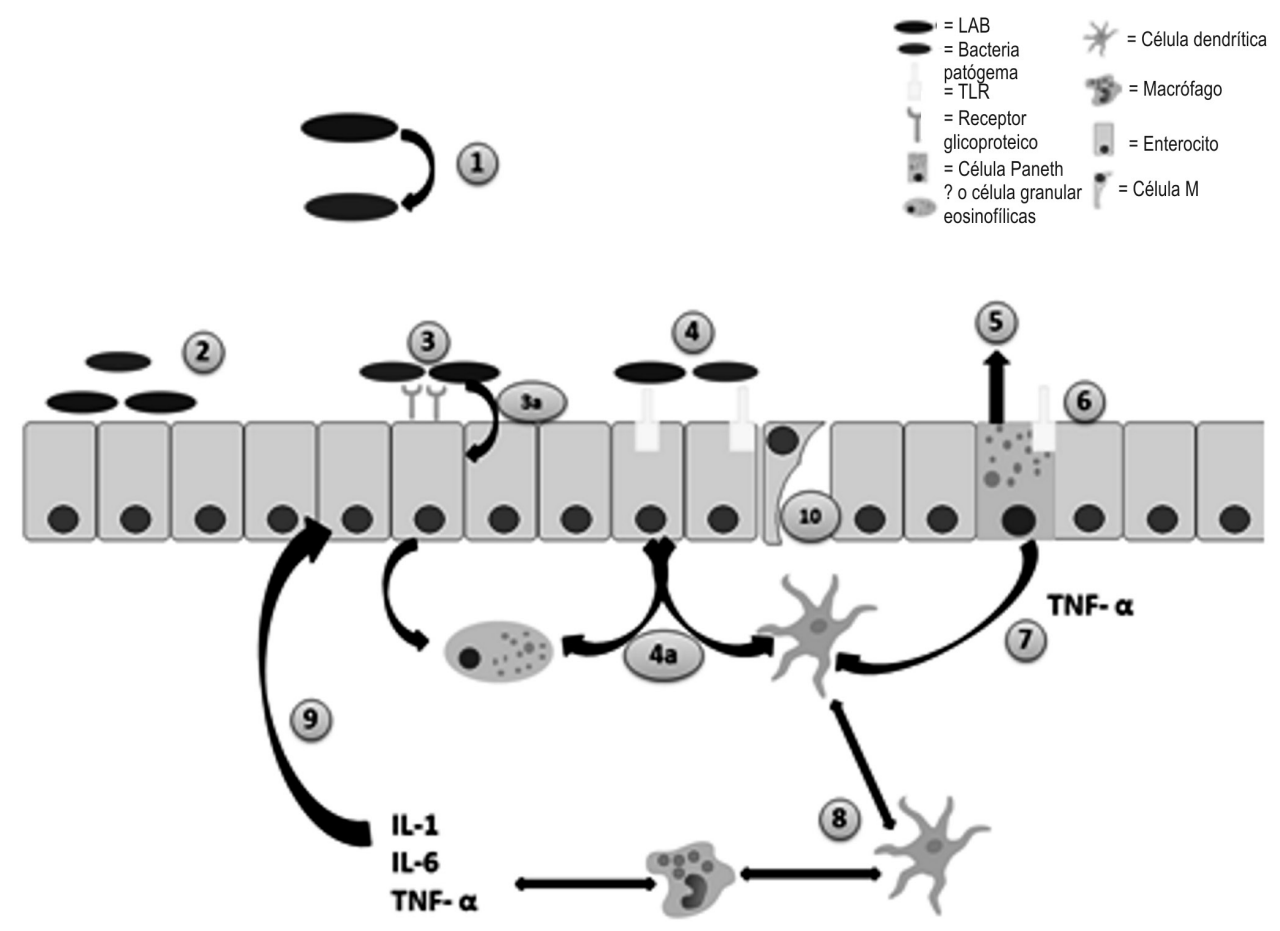

Figura 4. Esquema propuesto del mecanismo de acción de los probióticos en peces. 1) Las LAB (verdes) son capaces de actuar sobre las potencialmente patógenas (violetas) mediante la secreción de enzimas y algunos péptidos (e.g. bacteriocinas); 2 ) las LAB pueden competir por sitios de adhesión celular de los enterocitos; 3) tanto LAB como patógenas son reconocidas primariamente por los receptores glicosídicos (L-fucosa; glicosilación) de la superficie de los enterocitos, en la mayoría de los casos estimulados por la acción de las modulinas secretadas por las LAB (3a); 4) además se ha demostrado que los enterocitos expresan TLR (TLR4) pudiendo hacer translocación bacteriana y reconociendo tanto bacterias patógenas como LAB, este reconocimiento genera una señal intracelular que culmina con la síntesis de citoquinas proinflamatorias que estimulan tanto células dendríticas así como otras células inmunes asociadas a las mucosas; 5) la existencia de células Paneth (?) o células granulares eosinofílicas asociadas al epitelio, las cuales pueden vertir sus secreciones al lumen; 6) así como expresar TLR (TLR9) y proteínas NOD para el reconocimiento de PAMPs bacterianos; 7) las células granulares eosinofílicas (células Paneth?) son capaces de secretar TNF- $\alpha$ que su vez estimulan a células dendríticas que pueden reclutar células como macrófagos. Esta estimulación vía TLR puede inducir la producción de interferón tipo I el cual tiene propiedades antivirales así como de otras citoquinas (IL-1, IL-6); 9) esta secreción pueden retroalimentar a los enterocitos induciendo la expresión de más receptores; por último, se hace necesario investigar la existencia de células M (10) en peces, lo que permitiría vislumbrar nuevos mecanismo de homeostasis intestinal. 
ejemplo, sobre cuáles serían las cantidades y tiempos adecuados de suministro para mantener la respuesta inmune apropiada, ya que se ha visto que el suministro permanente y dosis muy elevadas de sustancias inmunoestimulantes puede tener incluso efectos adversos sobre la salud de los peces; también, se requiere la realización de trabajos que pongan a prueba el grado de protección de las sustancias ante un patógeno determinado, a través de infecciones experimentales, evaluando la supervivencia de los peces como parámetro más acertado de la respuesta de todo el organismo en condiciones de campo. Adicionalmente, se deben tener en cuenta diferencias intraespecíficas de los peces dentro de los estudios, por lo cual, estos deben considerar cada una de las especies de interés.

Aunque existen en la actualidad gran cantidad de trabajos acerca del efecto benéfico de probióticos e inmunoestimulantes en el mundo, poco se ha hecho en Colombia, esto aunado a que varias sustancias inmunoestimulantes evaluadas con rigor científico, son de alto costo y difícil consecución debería motivar trabajos de investigación enfocadas al uso de sustancias y microrganismos que puedan extraerse y producirse localmente y de manera industrial sin afectar de forma importante los costos de producción, sustancias que puedan incluirse en el pienso para facilitar el proceso de asimilación sin manipulación y estrés de los animales; investigaciones rigurosas y confiables para emplearlos como estrategia preventiva viable para mejorar la respuesta inmune de los peces, reduciendo así, problemas sanitarios, ambientales y pérdidas económicas en los sistemas de cultivo regionales.

\section{Referencias}

Ainsworth AJ. A beta-glucan inhibitable zymosan receptor on channel catfish neutrophils. Vet Immunol Immunopathol 1994; (41): 141-152.

Aly S, Ahmed Y, Ghareed A, Mohamed M. Studies on Bacillus subtilis and Lactobacillus acidophilus, as potential probiotics, on the immune response and resistance of Tilapia nilotica (Oreochromis niloticus) to challenge infections. Fish Shellfish Immunol 2008; 25: 128-136.

Balcazar J, Vendrell D, de Blas I, Ruiz I, Girones O, Muzquia J. Immune modulation by probiotic strains: quantification of phagocytosis of Aeromonas hydrophila by leukocytes isolated from gut of rainbow trout (Oncorhynchus mykiss) using a radiolabelling assay. Comp Immunol Microbiol Infect Dis 2006; 29: 335-343.

Brown G, Gordon S. Fungal $\beta$-glucans and mammal immunity. Immunity 2003; 19:311-315.

Caipang C M, Lazado C, Brinchmann M, Kiron V. Transcription of selected immune-related genes in spleen cells of cod, Gadus morhua following incubation with alginic acid and $\beta$-glucan. J Exp Mar Bio. Ecol. In press 2012.

Chang C, Liu W. Short Communication: An evaluation of two probiotic bacterial strains, Enterococcus faecium SF68 and BaciIlus toyoi, for reducing edwardsiellosis in cultured European eel, Anguilla anguilla L. J Fish Dis. 2002; 25: 311-315.

Chen J, Seviour R. Medicinal importance of fungal B-(1-3), (16)-glucans. Mycol Res. 2007; 111:635-652.

Dalmo R, Bøgwald J. ß-glucans as conductors of immune symphonies. Review. Fish Shellfish Immunol. 2008; 25:384-396.

Denney KM, Brown GD. The role of the B-glucan receptor Dectin-1 in control of fungal infection. J Leukoc Biol. 2007 (82); 253-258.

El-Boshy M, El-Ashram A, AbdelHamid FM, Gadalla HA. Immunomodulatory effect of dietary Saccharomyces cerevisiae, $\beta$-glucan and laminaran in mercuric chloride treated Nile tilapia (Oreochromis niloticus) and experimentally infected with Aeromonas hydrophila. Fish shellfish Immunol. 2010; 28: 802-808.

Engstad RE, Robertsen B. Specificity of a ß-glucan receptor on macrophages from Atlantic salmon (Salmo salar L.). Dev Comp Immunol. 1994; 18:397-408.

Falco A, Chico V, Marroquí L, Perez L, Coll JM, Estepa A. Expression and antiviral activity of a $\beta$-defensin-like peptide identified in the rainbow trout (Oncorhynchus mykiss) EST sequences. Mol Immunol. 2008; 45: 757-765.

Falco A, Frost P, Miest J, Pionnier N, Irnazarow I, Hoole D. Reduced inflammatory response to Aeromonas salmonicida infection in common carp (Cyprinus carpio L.) fed with $\beta$-glucan supplements. Fish shellfish Immunol In press, 2012.

FAO. Informe del $28^{\circ}$ período de sesiones del Comité de Pesca. Roma, 2-6 de marzo de 2009. FAO Informe de Pesca y Acuicultura. No. 902. Roma, FAO. 2009. 64p.

FAO/WHO. Report of a joint FAO/WHO expert consultation on evaluation of health and nutritional properties of probiotics in food including powder milk with live lactic acid bacteria. 2001, Cordoba, Argentina.

Fawcett DW. 1987. A textbook of histology. 11th Edition. WB Saunders Company. p656

Fitzgerald K, Rowe D, Golenbock D. Endotoxin recognition and signal transduction by the TLR4/MD-2 complex. Microbes Infect 2004; 6:1361-1367.

Freitas M, Tavan E, Cayuela C, Diop L, Sapin C, Trugnan G. Host pathogen cross-talk. Indigenous bacteria and probiotics also play the game. Biology of the Cell 2003; 95: 503-506

Fuller, R. A review: probiotics in man and animals. J App/ Bacteriol 1989;66:365-378.

Gunimaladevi I, Savan R, Sakai M. Identification, cloning and characterization of interleukin-17 and its family from zebrafish. Fish Shellfish Immunol. 2006 (21):393-403. 
Harikrishnan R, Balasundaramb C, Heo MS. Effect of probiotics enriched diet on Paralichthys olivaceus infected with lymphocystis disease virus (LCDV). Fish Shellfish Immunol. 2010a; 26:368-376.

Harikrishnan R, Balasundaramb C, Heo MS. Lactobacillus sakei BK19 enriched diet enhances the immunity status and disease resistance to Streptococcosis infection in kelp grouper, Epinephelus bruneus. Fish Shellfish Immunol. 2010b; 29:10371043.

Harikrishnan R, Balasundaramb C, Heo MS. Probiotics and herbal mixtures enhance the growth, blood constituents, and nonspecific immune response in Paralichthys olivaceus against Streptococcus parauberis. Fish Shellfish Immunol. 2011a; 31: 310-317.

Harikrishnan R, Kim MC, Kim J C, Balasundaramb C, Heo MS. Immunomodulatory effect of probiotics enriched diets on Uronema marinum infected olive flounder. Fish Shellfish Immunology. 2011b; 30: 964-971.

Haroun E, Goda A, Chowdhury K. Effect of dietary probiotic Biogens supplementation as a growth promoter on growth performance and feed utilization of Nile tilapia Oreochromis niloticus (L.). Aquaculture Res. 2006; 37: 1473-1480.

Iliev D,Roach J,Mackenzie S,Planas J, Goetz F. Endotoxin recognition: In fish or not in fish?.FEBS Lett. 2005; 579(29): 65196528.

Irie T, Watari S, Iwasaki T, Kodama H. Binding of Vibrio anguillarum to neutral glycosphingolipids from intestinal mucosa or rainbow trout (Oncorhynchus mykiss). J Vet Med Sci. 2004; 66(2): 205-208.

Kapetsky JM., Nath SS. Una evaluación estratégica de la potencialidad para la piscicultura dulceacuícola en América Latina. FAO. 1997

Kekkonen R. Immunomodulatory Effects of Probiotic Bacteria in Healthy Adults. Academic Dissertation. Institute of Biomedicine, Department of Viral Diseases and Immunology 2008. Helsinki, Finland.

Keshav S. Paneth cells: leukocyte-like mediators of innate immunity in the intestine. J Leukocyte Biol. 2006; 80: 500-508

Kim D, Austin B. Innate immune responses in rainbow trout $(\mathrm{On}$ corhynchus mykiss, Walbaum) induced by probiotics. Fish Shellfish Immunol. 2006; 21:513-524.

Kim YK, Zhang FQ. Effect of -glucan on activity of antioxidant enzymes and $\mathrm{Mx}$ gene expression in virus infected grass carp. Fish Shellfish Immunol. 2009; 27:336-340

Kunttu $\mathrm{H}$, Valtonen $\mathrm{E}$, Suomalainen LR, lelma J, Jokinen IE. The efficacy of two immunostimulants against Flavobacterium columnare infection in juvenile rainbow trout (Oncorhynchus mykiss). Fish Shellfish Immunol 2009; 26:850-857

Lelouard H, Reggio H, Mangeat P, Neutra M, Montcourrier P. Mucin-related epitopes distinguish $M$ cells and enterocytes in rabbit appendix and Peyer's patches. Infect Immun.1999; 67(1): 357-367.
Lin S, Pan Y, Luo L, Luo L. Effects of dietary b-1,3-glucan, chitosan or raffinose on the growth, innate immunity and resistance of koi (Cyprinus carpio koi). Fish Shellfish Immunol. 2011; 31: 788-794.

López-Boado Y-S, Wilson CL, Hooper LV, Gordon Jl, Hultgren SJ, Parks WC. Bacterial exposure induces and activates matrilysin in mucosal epithelial cells. J Cell Biol. 2000; 148 (6): 13051315.

Lundén T, Bylund G. Effect of sulphadiazine and trimethropin on the immune response of rainbow trout (Oncorhynchus mykiss). Vet Immunol Immunopathol. 2002; 85: 99-108.

Ma C W, Cho YS, Oh KH. Removal of pathogenic bacteria and nitrogens by Lactobacillus spp. JK-8 and JK-11 Aquaculture. 2009; 287: 266-270

Ma B, Simala-Grant JL, Taylor .Fucosylation in prokaryotes and eukaryotes. Glycobiology. 2006; 16(12): 158-184.

Madigan M, Martinko J, Dunlap P, Clark D. Brock, 2009. Biología de los microorganismos. Addison Wesley. 12 edición. 12591260.

Maldonado CG, De Moreno A, Vinderola G, Bibas ME, Perdigon G. Proposed model: Mechanisms of immunomodulation induced by probiotic bacteria. Clin Vacc Immunol. 2007; 14(5): 485-492

Mantovani M, Bellini M, Angeli J, Oliveira R, Silva A, Ribeiro L. $\beta$-Glucans in promoting health: Prevention against mutation and cancer. Mutation Res. 2008; 658:154-161

Martínez M, Devia A, Ospina A, Reyes C, Villamil L. Nuevos indicios sobre La idoneidad de los géneros Bacillus y Lactobacillus como probióticos en el cultivo de tilapia nilótica. Resúmenes de trabajos presentados Nutrición y Alimentación. Memorias: IV Congreso Colombiano de Acuicultura "Comercialización y Potencial de Mercadeo de los Recursos Acuícolas". Rev Colomb Cien Pec. 2008b; 21(3):493494.

Martínez M, Devia A, Ospina A, Reyes C, Villamil L. Relación entre el uso de Bacillus y Lactobacillus y el nivel de sobrevivencia de tilapia nilótica durante desafíos experimentales con bacterias patógenas. Resúmenes presentados patología y sanidad acuícola. Memorias: IV Congreso Colombiano de Acuicultura "Comercialización y Potencial de Mercadeo de los Recursos Acuícola. Rev Col Cien Pec 2008a; 21(3):499.

Matsumura A, Saito T, Arakuni M, Kitazawa H, Kawai T, Itoh T. 1999. New binding assay and preparative trial of cell-surface lectin from Lactobacillus acidophilus group lactic acid bacteria. J Dairy Sci. 1999; 82: 2525-2529.

Maury J, Bernadac A, Rigal A, Maroux S. Expression and glycosylation of the filamentous brush border glycocalyx (FBBG) during rabbit enterocyte differentiation along the crypt-villus axis. J Cell Sci. 1995; 108: 2705-2713.

Misra C, Mukherjee S, Pattnaik P. Effect on long term administration of dietary b glucan on immunity, growth and survival of Labeo rohita. Aquaculture. 2006; 255: 86-94. 
Nakao M, Fujiki K, Kondo M, Yano T. Detection of complement receptors on head kidney phagocytes of the common carp $C y$ prinus carpio. Fish Sci. 2003; 69: 929-935.

Nayak S. Probiotics and immunity: A fish perspective Review. Fish Shellfish Immunol. 2010; 29: 2-14

Nguyen T, Dierckens K, Sorgeloos P, Bossier P. A Review of the functionality of probiotics in the larviculture. Food Chain Mar Biotech. 2008; 10: 1-12.

Nikoskelainen S, Ouwehand A, Bylund G, Salmien S, Lilius E. Immune Enhancement in rainbow trout (Oncorhynchus mykiss) by potential probiotic bacteria (Lactobacillus rhamnosus). Fish Shellfish Immunol. 2003; 15:443-452.

Nopadon P, Kobayashi T, Katagiri T, Maita M, Endo M. Protective effects and mechanisms of a probiotic bacterium Lactobacillus rhamnosus against experimental Edwardsiella tarda infection in tilapia (Oreochromis niloticus). Vet Immunol Immunopathol. 2006; 113: 339-347.

Novoa B, Bowmanb TV, Zon L, Figueras A. LPS response and tolerance in the zebrafish (Danio rerio). Fish Shellfish Immunol. 2009; 26:326-331

FAO. 21. Oficina de Prensa. Países lanzan la Red de Acuicultura de las Américas con apoyo técnico de FAO. Santiago de Chile, 26 de marzo de 2010. Disponible en internet: www.rlc.fao. org/es/prensa/coms/2010/34.pdf

Palic D, Andreasen C, Herolt D, Menzel B, Rot J. Immunomodulatory effects of -glucan on neutrophil function in fathead minnows (Pimephales promelas Rafinesque, 1820) Dev Comp Immunol. 2006; 30:817-830.

Palm NW, Medzhitov R. Antifungal defense turns 17. Nat Immunol. 2007; 8: 549-551.

Panigrahi A, Kiron V, Satoh S, Hirono I, Kobayashi T, Sugita H, Puangkaew J, Aoki T. Immune modulation and expression of cytokine genes in rainbow trout Oncorhynchus mykiss upon probiotic feeding. Dev Comp Immunol. 2007; 31:372-382.

Panigrahi A, Kirona V, Puangkaewa J, Kobayashib J, Satoha S, Sugita $\mathrm{H}$. The viability of probiotic bacteria as a factor influencing the immune response in rainbow trout Oncorhynchus mykiss. Aquaculture. 2005, 243:241-254.

Patiño PJ. 2009. Estructura y función de la respuesta inmune: una visión integral. En: Rugeles MT, Patiño PJ, Montoya CJ. Inmunología. Una ciencia activa. Segunda edición. Universidad de Antioquia, Pp. 3-25.

Pérez R G, Figueroa J, Quintero L G. Efecto de la inclusión de dos probióticos y un prebiótico en la dieta para la alimentación de alevinos de cachama blanca (Piaractus brachypomus). En: Memorias II Congreso Colombiano de Acuicultura. X Jornada de Acuicultura. Retos frente a la globalización de mercados. Universidad de los Llanos, Villavicencio, Octubre 27 a 29 de 2004.

Picchietti S, Fausto AM, Randelli E, Carnevali O, Taddei A, Buonocore F, Scapigliati G, Abelli L. Early treatment with LactobaciIlus delbrueckii strain induces an increase in intestinal T-cells and granulocytes and modulates immune-related genes of larval Dicentrarchus labrax (L.). Fish Shellfish Immunol. 2009; 26: $368-376$.
Picchietti S, Mazzini M, Tadde A, Renna R, Fausto A, MuleroV, Carnevali O, Cresci A, Abelli L. Effects of administration of probiotic strains on GALT of larval gilthead seabream: Immunohistochemical and ultrastructural studies. Fish Shellfish Immunol 2007; 1-11.

Pirarat N, Pinpimai K, Endo M, Katagiri T, Ponpornpisit A, Chansue $\mathrm{N}$, Maita N. Modulation of intestinal morphology and immunity in nile tilapia (Oreochromis niloticus) by Lactobacillus rhamnosus GG. Res Vet Science. 2001; 91:92-97.

Raa J. The use of immune-stimulants in fish and shellfish feeds. En: Cruz -Suárez, L.E., Ricque-Marie, D., Tapia-Salazar, M., Olvera-Novoa, M.A. y Civera-Cerecedo, R, (Eds.). Avances en Nutrición Acuícola V. Memorias del V Simposium Internacional de Nutrición Acuícola. 19-22 Noviembre, 2000. Mérida, Yucatán, México.

Refstie S, Baeverfjord G, Seim RR, Elvebø O. Effects of dietary yeast cell wall $\beta$-glucans and MOS on performance, gut health, and salmon lice resistance in Atlantic salmon (Salmo salar) fed sunflower and soybean meal. Aquaculture. 2010; 305: 109-116.

Rodríguez F, Esteban M, Meseguer J, Bravo M, Gómez G, Rojas-Luna T, Jiménez G, Balcázar J. Estrategias de control de enfermedades en Acuicultura II Congreso Iberoamericano Virtual de Acuicultura CIVA 2003 (http://www.civa2003.org), 624-654.

Rodríguez I, Chamorro I, Novoa B, Figueras A. -Glucan administration enhances resistance and some innate immune responses in zebrafish (Danio rerio). Fish Shellfish Immunol. 2008; 25:731-739.

Rondón I. Inmunoestimulantes en Medicina Veterinaria. Orinoquia 2004; 8(2): 56-75.

Rothfuchs AG, Bafica A, Feng CG, Egen JG, Williams DL, Brown GD, et al. Dectin-1 interaction with Mycobacterium tuberculosis leads to enhanced IL-12p40 production by splenic dendritic cells. J Immunol. 2007; (179); 463-3471.

Rumio C, Besusso D, PalazzoM, Selleri S, Sfondrini L, Dubini F, Ménard S, Balsari A. Degranulation of Paneth cells via toll-like receptor 9. Amer J Pathobiol. 2004; 165(2): 373-381.

Saha S, Narayan R, Sukanta R, Sen K, Kumar A. Characterization of cellulase-producing bacteria from the digestive tract of tilapia Oreochromis mossambicus (Peters) and grass carp, Ctenopharyngodon idella (Valenciennes). Aquaculture Res. 2006; 37:380-388.

Sahoo P. Role of immunostimulants in disease resistance of fish. CAB Reviews: Perspectives in Agriculture, Veterinary Science, Nutrition and Natural Resources. 2007;(2):45.

Salinas I, Díaz-Rosales P, Cuesta A, Meseguer J, Chabrillón M, Morínigo $A$, Esteban $M$. Effect of heat-inactivated fish and nonfish derived probiotics on the innate immune parameters of a teleost fish (Sparus aurata L.). Vet Immunol Immunopathol. 2006; 111:279-286.

Salinas I, Myklebust R,Esteban M.A, Olsen R. Meseguer J, Ringø E. In vitro studies of Lactobacillus delbrueckii subsp. lactis in Atlantic salmon (Salmo salar L.) foregut: Tissue responses and evidence of protection against Aeromonas salmonicida subsp. salmonicida epithelial damage. Vet Microbiol. 2008; 128:167-177. 
Selvaraj V, Sampath K, Sekar V. Adjuvant and Inmmunomodulatory effect of -glucan administration in combination with LPS enhances survival and some immune parameters in carp challenge with A. hydrophila. Vet Immunol Immunopathol. 2006; 114:15-24.

Selvaraj V, Sampath K, Sekar V. Administration of yeast glucan enhances survival and some non-specific immune parameters in carp (Cyprinus carpio) infected with Aeromonas hydrophila. Fish Shellfish Immunol. 2005b; 19:293-306.

Selvaraj V, Sampath K, Sekar V. Use of glucan from Saccharomyces cerevisiae as an immunostimulant in carp: impact on hematology, phagocyte function, and infection with Aeromonas hydrophyla. Israeli J Aquaculture. 2005a; 57(1):39-48.

Serezlí R, Ça irgan H, Okumu Ü, Akhan S, Balta F. The effect of oxytetracycline on non-specific immune response in Sea Bream (Sparus aurata L. 1758). Turk J Vet Anim Sci. 2005; 29: 31-35

Sharon, N. (2006). Carbohydrates as future anti-adhesion drugs for infectious diseases. Biochim. Biophys. Acta, 1760; 527-537.

Son VM, Chang CC, Wu MC, Guu YK, Cheng CH. Dietary administration of the probiotic, Lactobacillus plantarum, enhanced the growth, innate immune responses, and disease resistance of the grouper Epinephelus coioides. Fish Shellfish Immunol. 2009; 26:691-698.

SOFIA. Estado Mundial de la Pesca y la Acuicultura - 2008. FAO Organización de las Naciones Unidas para la Agricultura y la Alimentación, Roma, 2009.

SveinbjØrnsson B, Olsen R, Paulsen S. Immunocytochemical localization of lysozyme in intestinal eosinophilic granule cells (EGCs) of atlantic salmon, Salmo salar L. J Fish Dis. 1996; 19: 349-355.

Swain P, Nayak S, Nanda P, Dash S.Biological effects of bacterial lipopolysaccharide (endotoxin). in fish: A review. Fish Shellfish Immunol. 2008; 25:191-201.

Sullivan C, Charette J, Catchen J, Lage C R, Glasson G, Postlethwalt J, Millard P, Kim C. The gen history of Zebrafish t/r4a and t/r4b is predictive of their divergent functions. J Immunol. 2009; 183 (9): 5896-5908.

Tada R, Ikeda F, Aokia K, Yoshikawa M, Katoa Y, Adachi Y, Taniokab A, Ishibashia K, Tsubakib K, Ohno N. Barley derived $\beta$-d glucan induces immunostimulation via a dectin-1-mediated Pathway. Immunol Letters. 2009; 123: 144-148
Taoka Y, Maeda H, Jo J, Kim S, Park S, Yoshikawa T, Sakata T. Use of live and dead probiotic cells in tilapia Oreochromis niloticus. Fisheries Sci. 2006; 72: 755-766.

Tardy F, Louisot P, Martin A. Effect of dietary fiber at weaning on protein glycosylation in the rat small intestine. Int J Biochem Cell Biol. 1195; 27(4): 403-413.

Tizard I. Veterinary Immunology. Eight Edition. Saunders Elsevier. 2009. Texas.

Umesaki Y, Ohara M. 1989. Factors regulating the expression of the neutral glycolipids in the mouse small intestinal mucosa. Biochim Biophys Acta. 1989; 1001: 163-168.

Vásquez, J. González M, Murado M. Effects of lactic acid bacteria cultures on pathogenic microbiota from fish. Aquaculture. $2005 ; 245: 149-161$.

Verschuere L, Rombaut G, Sorgeloos P, Verstraete W. Probiotic bacteria as biological control agents in aquaculture. Microbiol Mol Rev 2000; 64:655-671.

Volman J, Ramakers J, Plat J. Dietary modulation of immune function by $\beta$-glucans. Physiol Behav. 2008; 94: 276-284.

Wang Y, Zi-Qiang T, Jiang-Tao Y, Wei-Fen Li. Effect of probiotics, Enterococcus faecium, on tilapia (Oreochromis niloticus). growth performance and immune response. Aquaculture. 2008; 277(3-4): 203-207.

Whittington R, Lim C, Klesius P. Effect of dietary $\beta$-glucan levels on the growth response and efficacy of Streptococcus iniae vaccine in Nile tilapia, Oreochromis niloticus. Aquaculture. $2005 ; 248: 217-225$.

Yanbo W, Zirong X. Effect of probiotics for common carp (Cyprinus carpio) based on growth performance and digestive enzyme activities. AFST. 2006; 127:283-292.

Zou J, Mercier C, Koussounadis A, Secombes C. Discovery of multiple beta-defensin like homologues in teleost fish. Mol Immunol. 2007; 44: 638-647

Zhang Z, Swain T, Bøgwald J, Dalmo R. Kumari J. Bath immunostimulation of rainbow trout (Oncorhynchus mykiss) fry induces enhancement of inflammatory cytokine transcripts, while repeated bath induce no changes. Fish Shellfish Immunol. 2009; 26: 677-684. 